\title{
Statistical Analysis of the Demographic Ageing Process in the EU Member States, Former Communist Countries
}

\author{
Dorel Săvulea \\ University of Craiova \\ Department of Informatics \\ Craiova, Romania
}

\author{
Nicolae Constantinescu \\ University of Craiova \\ Department of Informatics \\ Craiova, Romania
}

\begin{abstract}
The aim of this paper is to make an analysis and a comparative study of the demographic ageing process in the former communist countries which are currently EU member states. Taking into account the complexity of the phenomenon, the study approaches only a part of the indices involved in this process. According to the structure of the population on groups of ages and sexes, the population pyramid is built and in this context we carried out various analyses and comparisons among countries. Further we approach determining demographic factors for the ageing process of the population, as for example the evolution of the young population, the mortality rate and the life expectancy and the changes in the population structure are pointed out with the help of the demographic dependency rate. There have been made a series of statistical correlations and predictions which allowed for a more concrete explanation of the evolution of the demographic ageing phenomenon.
\end{abstract}

Keywords- component; statistical analysis; demographic analyse; statistical correlation.

\section{INTRODUCTION}

Demography is considered a social science, with a unitary character, its main objective being the study of population and demographic phenomena. Its basis was set by John Graunt (1620-1674) and it can be defined as the science which studies the population dynamics which comprises the size, structure and demographic age phenomenon as well as its implications.

In the last two decades, the demographic ageing process has increased on a global level which represents an important growth of the aged population segment of the total number of population employed in the socio-economic field. The phenomenon is also found in the EU member states, with special features due to the socio-cultural and economic systems [1].

The population aging combined with the decrease of the birth rate is one of the major problems from an economic, budgetary and social point of view. Some EU countries are developing some programs to fight against this phenomenon especially through reforms of the retirement, health and social care systems.

Due to the lack of such institutional changes and of adequate policies this ageing process will have a strong impact on the economic growth leading to the growth of the public expenses but also of the ones from the infrastructure, education etc.

The debates from the European Council have led to the conclusion that there is a need to manage the effect of the population aging on the economies of the EU countries. Therefore, the Hampton Court Summit from October 2008, the renewed Lisbon Strategy, the new EU development strategy have set the need for a long term coordination of the actions between the member countries in what the retirement, health and care systems are concerned as well as a strategy for the increase of the young population and of the public finances in the context of the Stability and Growth Pact [8]. These debates have shown a margin of manoeuvre of almost 10 years when the labour force continues to grow, and this fact will allow the accomplishment of some specific reforms for an aging society.

This paper seeks to identify, analyse and predict the evolutions of the phenomenon in the former communist countries, now EU member states. It has been conducted a comparative study of the indices involved and the consequences of this process have also been presented. For the statistical data processing we used analysis and data processing software as well as MINITAB and SPSS.

\section{STATISTICAL DEMOGRAPHIC IMPLIED MODELS}

\section{A. Study on population. Descriptive notions.}

For the analysis of the aging process the definition of some concepts is needed and also their calculation methodology.

For the concept number of population we distinguish two categories: the number of registered population and the calculated number of population.

\section{Definition 1 [ 11]}

a) the registered number of population is the number determined after the population survey representing the physical number of population at the moment of registration. With the help of this number one can determine the density of population as well as the indices for the average rhythm of growth of the population;

b) the calculated number of population is its number determined with the help go various calculation methods for a date or a given period, for which there are no information; 
From the point of view of the dynamic or time series, the number of population might be an indicator for the moment (the number of population on the date of the survey or at another moment), but also interval indicator (the average number of population in a certain period), for most of the descriptive statistical data which require the use of the number of population as an interval indicator. The calculation formula for the population number is the following:

$$
\begin{gathered}
\mathrm{P} 1=\mathrm{P} 0+(\mathrm{N}(0,1)-\mathrm{M}(0,1))+(\mathrm{I}(0,1)-\mathrm{E}(0,1))= \\
\mathrm{P} 0+\Delta \mathrm{sn}+\Delta \mathrm{sm}
\end{gathered}
$$

where

P0 şi P1 - population number at two different dates;

$\mathrm{N}(0,1)$ - the number of living new born babies in the 0,1 interval;

$\mathrm{M}(0,1)$ - the number of deceased in the 0,1 interval;

$\mathrm{I}(0,1)$ - the number of immigrants in that population in the 0,1 interval;

$\mathrm{E}(0,1)$ - the number of emigrants in that population in the 0,1 interval;

$\Delta \mathrm{sn}$ - the natural growth determined as a difference $\mathrm{N}(0,1)-$ $\mathrm{M}(0,1)$;

$\Delta \mathrm{sm}$ - the migrating growth determined as a difference $\mathrm{I}(0,1)$ $-\mathrm{E}(0,1)$.

The two basic demographic characteristics in the analysis of the population structure are the sex and the age. The population structure represents a statistical distribution of a population according to the qualitative characteristic sex in two sub-populations: masculine and feminine. The population structure according to age represents a statistical distribution of a population according to the quantitative characteristic age. Usually, for the demographic calculations, population is distributed on the following intervals: $0-4 ; 5-9 ; 10-14 ; \ldots ; 95-$ $99 ;+100$.

The most important tool for the analysis of the structure according to age is represented by the so called population pyramid, used in the study of the process of demographic aging of the population. The pyramid designates a special graphical representation of the population distribution according to age, consisting of two charts, one for the masculine and the other for the feminine population. On the vertical we can see the age of the population, from 0 years old (the pyramid base) to 100 years old (its top), in the left there is the masculine population and in the right the feminine one.

As a consequence of the population decrease due to ageing, the chart becomes a triangle, thus explaining the name of population pyramid.

\section{B. Population ageing}

The demographic ageing of the population represents a demographic process which relies in the growth of the old population combined with the decrease in the young population; usually the proportion of the adult population remains unchanged for a long time.

The determining factors of the ageing process are the decrease of the birth rate and the mortality.
In this context, it has to be mentioned the fact that the demographic ageing of the population due to the decrease in the birth rate is also known under the name of ageing at the bottom of the pyramid, and the one resulted from the decrease of mortality and consequently to the growth of the average life expectancy is called ageing on the top of the pyramid.

In order to study the demographic ageing process, according to the International Labour Organization(ILO) and EUROSTAT standard, the population is divided into three groups: 0-14 years old (young population); 15-64 years old (adult population or, in some references, named people of working age); 65+ years old (old population). The share in percentage is calculated according to the formulae:

$$
\begin{aligned}
& \mathrm{Pt}=(\mathrm{P} 0-14 / \mathrm{Nt}) \cdot 100 \\
& \mathrm{PV}=(\mathrm{P} 65+/ \mathrm{Nt}) \cdot 100
\end{aligned}
$$

where

$\mathrm{Pt}$ - percentage share of the young population;

$\mathrm{Pv}$ - percentage share of the old population;

$\mathrm{Nt}$ - total number of population

P0-14 - total number of population with ages between 0-14 years old,

It is thought that a population where the 65 years old groups and over has less than $7 \%$ of the total cannot be regarded as young from a demographic point of view. Under the circumstances when the share of the elder people fluctuates between $7-12 \%$, that population is in a full demographic ageing process, and when it exceeds $12 \%$, we are talking about a demographic aged population.

Due to the fact that the structure according to ages is directly involved in setting the productive potential of the society, it is recommended to set a dependency ratio, which measures the pressure exerted by the population from the inactive age groups on the adult population. This ration expresses the number of young and old people from a population below and over the limit of the working age which goes to 100 people which are able to work, belonging to that population.

The dependency ratio is determined according to the relation:

$$
\mathrm{Rd}=[(\mathrm{P} 0-14+\mathrm{P} 65+) / \mathrm{P} 15-64] \cdot 100
$$

The demographic dependency ratio is sometimes divided into the old age dependency ratio (the ration between the 65 years old population and the population between 15-64 years old), written down as Rdv and the young age dependency ratio (the ration between the population below 15 years old and the population between 15-64 years old), written down as Rdc.

$$
\begin{aligned}
& \mathrm{Rdv}=\mathrm{P} 65+/ \mathrm{P} 15-64 \cdot 100 \\
& \mathrm{Rdc}=\mathrm{P} 0-14 / \mathrm{P} 15-64 \cdot 100
\end{aligned}
$$

The structure of the population of the countries might be different according to the fertility, mortality and migration models, from the past and present, which are characteristic for each country, thus distinguishing four general profiles of the population structure, Fig. 1. 


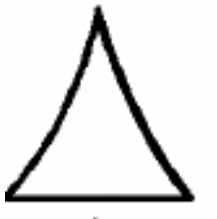

1

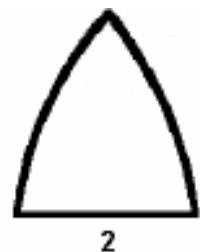

Figure 1. Types of people pyramids

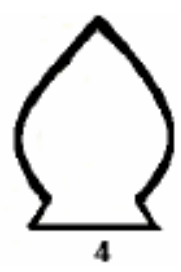

Type 1, also called circumflex pyramid is specific for a young population from a demographic point of view, with a high birth rate and mortality.

Type 2, also called rick is characteristic for the countries where the ageing process is not advanced and the fertility is relatively high.

Type 3, the urn pyramid, represents a population with high demographic ageing symptoms, as a consequence of the significant decrease of fertility, leading to the de-population process.

Type 4, the clubs pyramid is characteristic for a population which is getting younger, after a demographic ageing process.

The general mortality rate (RGM) [2,10]. It is calculated as a ratio between the number of deceases in a period (usually year) and the average number of population from that year. The formula is:

where

$$
R G M=(D / P) \cdot 1000
$$

$\mathrm{D}$ - amount of deceases;

$\mathrm{P}$ - average number of population;

RGM expresses the number of deceases for 1.000 inhabitants in a random population, in a year.

The mortality rate on ages (RMV). It is calculated as a ratio between the number of deceases at a certain age (age group), in a given period of time (usually a year) and the total number of population of that age (age group). The formula is:

where

$$
\mathrm{RMV}=(\mathrm{Dv} / \mathrm{Pv}) \cdot 1.000
$$

Dv -the number of deceases for the young population (age group) v;

$\mathrm{Pv}$ - the number of old population of $x$ years old or from the $v$ age group;

Mortality rate on sexes (RDM, RDF). It is calculated by reporting the number of deceases registered for the male and female persons, in a given period of time, to the number of persons belonging to that sex.

$\mathrm{RDM}=(\mathrm{Dm} / \mathrm{Pm}) \cdot 1.000$ or $\mathrm{RDF}=(\mathrm{Df} / \mathrm{Pf}) \cdot 1.000$

where

$\mathrm{Pf}, \mathrm{Pm}$ - the number of women and men;

$\mathrm{Dm}$, Df - the number of deceases registered around men, women;

\section{Statistical models}

The causality ratios among different demographic indices can be quantified and analysed with the help of correlation [7].
The obtained information offers the possibility of knowing the following aspects:

- The existence of the causality ratios among phenomena ;

- The contribution of each factor to the global variability of the effect phenomena;

- The intensity of the causes connections between the socio-economic phenomena and processes;

- The evolving tendencies of the correlation among phenomena.

In analyzing the correlation we take into account two main aspects:

- regression - which helps to determine the contribution of the determining factors to the variability of the effect phenomena by using and interpreting the regression coefficients of the different statistical-mathematical functions;

- the intensity of correlation - synthesised with the help of the correlation coefficients.

For the simple correlation, the first aspect can be pointed out with the help of the following functions: linear - for the causal-linear connections; higher parabolic, hyperbolic, exponential, logarithmic, semi-logarithmic, logistic, etc- for non-linear causal connections. The simple correlation can be linear and non-linear according to the form of the tendencies of causal connections.

The linear regression analysis uses the linear function with the following formula:

$$
\begin{aligned}
& Y_{x}=a+b X \\
& \text { where } \\
& Y_{x} \text { - empirical values; }
\end{aligned}
$$

a- values of the resulting variable $Y$ determined outside the influence of the factorial variable $\mathrm{X}$;

b- regression coefficient which synthesises the growth or the decrease of the $\mathrm{Y}$ variable corresponding to a growth or a decrease of the $\mathrm{X}$ variable which is equal to the unit;

$\mathrm{X}$ - values $\mathrm{x} 1, \mathrm{x} 2, \ldots \quad \mathrm{xn}$ of the factorial variable $\mathrm{X}$.

In practice, in order to determine the contribution of some of the influential factors (the factorial variable) for the variability of the dependent phenomenon, the determination coefficient is used with the following calculation relation [7]:

$$
R^{2}=\frac{[\operatorname{cov}(X, Y)]^{2}}{\sigma_{x}^{2} \sigma_{y}^{2}}
$$

where $\sigma_{x}^{2}$ and $\sigma_{y}^{2}$ represent the dispersion of the variable $\mathrm{X}$, respectively $\mathrm{Y}$, and $\operatorname{cov}(X, Y)$ represents a measure of the degree in which the variation of a variable suits with the variation of the other variable.

In practice $\mathrm{R}^{2}$ is expressed in percentages.

The correlation coefficient $r$ points out the intensity of the causal connection between the two variables. Both 
coefficients rely on the Pearson relation; the determination coefficient is the square of the correlation coefficient. Therefore:

$$
r=\sqrt{R^{2}}=\frac{\operatorname{cov}(X, Y)}{\sigma_{x} \sigma_{y}}
$$

where $\sigma_{x}$ and $\sigma_{y}$ represent the standard deviations for the $\mathrm{X}$ and $\mathrm{Y}$ variables.

The correlation coefficient $r$ takes values between -1 and 1 with the following signification:

- values between 0 and 1 point out a direct correlation more and more intense as they are getting close to 1 ;

- values between 0 and -1 point out a reverse correlation more and more intense as they are getting close to -1 ;

- zero value points out the fact that there is no connection between these the two variables.

In order to test the signification of the correlation coefficient we are taking into account the verification of the null hypothesis $\left(H_{0}\right)$ - which is carried out with the help of the test Student $(t)$ - according to which there is no linear connection between the two variables. For this purpose, the parameter $t_{\text {calc }}$ is calculated with the formula:

$$
t_{\text {calc }}=r \sqrt{\frac{n-2}{1-r^{2}}}
$$

where

$r$-correlation coefficient;

$n$ - number of value pairs $x$ and $y$.

Value $t_{\text {calc }}$ is compared with the tabular value from table $t$ (Student), for $n-2$ degrees of liberty and the determined signification degree (usually $\alpha=0,05$ ).

The rejection region of the null hypothesis $H_{0}$, (for $n-2$ degrees of freedom) is:

$$
t_{\text {calc }}>t_{\alpha / 2, n-2} \text { sau } t_{\text {calc }}<-t_{\alpha / 2, n-2}
$$

If $H_{0}$ is rejected, we can draw the conclusion with an assumed risk (usually 5\%), that the value of the correlation coefficient does not equal 0 , that is between the two variables there is a significant connection or in other words, the correlation coefficient is statistically significant.

If $H_{0}$ is accepted, he correlation coefficient is not significant and between the variables there is a casual connection.

\section{STUDY ON THE POPULATION AGEING PHENOMENON}

\section{A. Analysis of the people pyramid and its implications}

Starting from the socio-economic problems of the former communist countries [6] and after a close analysis of the population evolution, there have been pointed out the long term effects in these countries. Table 1 presents the evolution of the population in Romania according to age groups between
1990 and 2010. The population pyramid was made based on this data, Fig. 2.

TABLE 1. STRUCTURE OF ROMANIAN POPULATION ON AGE GROUPS

\begin{tabular}{|c|r|r|r|r|}
\hline & \multicolumn{2}{|c|}{ Females } & \multicolumn{2}{c|}{ Males } \\
\hline year & $\mathbf{1 9 9 0}$ & $\mathbf{2 0 1 0}$ & $\mathbf{1 9 9 0}$ & $\mathbf{2 0 1 0}$ \\
\hline$<5$ & 886785 & 528013 & 924652 & 558232 \\
\hline 5 to 9 & 840908 & 515289 & 879347 & 544950 \\
\hline 10 to 14 & 965846 & 539363 & 1010941 & 566271 \\
\hline 15 to 19 & 926797 & 617312 & 967764 & 646396 \\
\hline 20 to 24 & 936256 & 845711 & 972155 & 880085 \\
\hline 25 to 29 & 695718 & 792972 & 730443 & 830994 \\
\hline 30 to 34 & 861549 & 861023 & 885855 & 908512 \\
\hline 35 to 39 & 847369 & 821235 & 861305 & 850839 \\
\hline 40 to 44 & 688201 & 832093 & 689118 & 844271 \\
\hline 45 to 49 & 629281 & 624305 & 609852 & 613462 \\
\hline 50 to 54 & 740820 & 776890 & 701320 & 728226 \\
\hline 55 to 59 & 705496 & 749830 & 659262 & 671502 \\
\hline 60 to 64 & 641048 & 598618 & 569872 & 509384 \\
\hline 65 to 69 & 545966 & 509613 & 418864 & 396275 \\
\hline 70 to 74 & 283694 & 547217 & 191709 & 382994 \\
\hline 75 to 79 & 324529 & 429818 & 217727 & 279752 \\
\hline 80 to 84 & 166702 & 272024 & 111738 & 162052 \\
\hline$>85$ & 73599 & 149767 & 48907 & 76896 \\
\hline
\end{tabular}

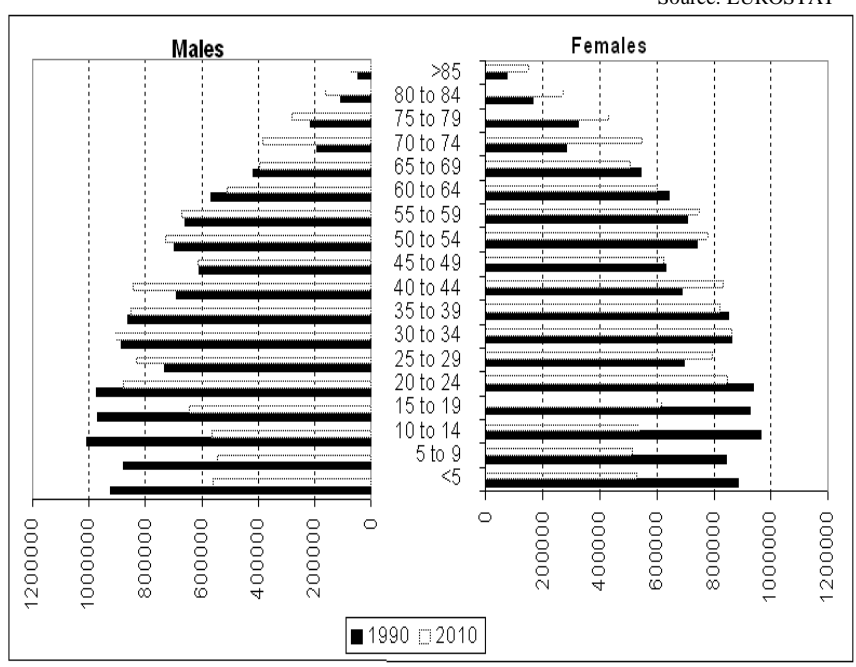

Figure 2. Population pyramid for Romania

A brief analysis of the type of pyramids for the two years shows that Romania has passed from a type 2 pyramid in 1990 when the ageing process when the ageing process was not too advances to a type 3 pyramid showing a population with advances symptoms of demographic ageing as a consequence of the significant decrease of fertility, announcing the process of de-population.

The ageing process is argues by the fact that the share of the population over 65 years old in the total number of population increase from $10,27 \%$ in 1990 to $14,94 \%$ in 2010 . If in 1990 the percentage of 10,27\% showed an ageing 
population, the one of $15 \%$ from 2010 overcomes substantially the limit of $12 \%$ (see previous section) which shows a demographic aged population.

At the same time, Fig. 2 shows that there was an ageing on the bottom of the pyramid due to the decrease of the birth rate. It is true that the share of the young population (0-14 years old) in the total number of population experienced a spectacular decrease from $23,73 \%$ in 1990 to $15,15 \%$ in 2010. The most obvious decrease can be noticed for the population from the age group 10-14 years old which is $44,06 \%$ smaller than that from 1990, followed by the $<5$ group (the age group younger than 5 years old) with a percentage of $40,03 \%$ and the $5-9$ years old group with $38,36 \%$. All these aspects show a decline of fertility in Romania in the 20 years from the fall of communism.

We notice that the principle of the people pyramid is fulfilled; according to this principle the adult population is relatively constant. There is a significant growth in the year 2010 for the 40-44 years old group $(21,71 \%)$ which is explained due to the birth rate policy carried out by the government in the 70's.

On the whole, the female population of 65 years old and over in Romania has increased in 2010 by 513949 people as opposed to 1990, while the male population has increased by only 309024 people. Although the male ratio ((number of men/number of women)*100) shows a decreasing trend of 70,91 men to 100 women in 1990 , of 68,01 to 100 women, in 2010, Romania holds one of the first places for this indicator. This fact is explained due to the life expectancy which is 77,1 years old for women and 69,6 years old for men 2009.

By taking over the information from the Eurostat database, the following results have been obtained for the other former communist countries which belong to EU [12].

The type of pyramid in Bulgaria is almost identical to the one in Romania, since it passed from a type 2 to a type 3 . We can say that the ageing process is stronger in Bulgaria because the share of the aged population in the total number of population was of $12,96 \%$ in 1990 and of $17,53 \%$ in 2010 , so in 1990 the population was already demographically aged. These high values explain why the top of the pyramid has a flattened form than the one of Romania.

In this case we also have an ageing on the bottom of the pyramid, the share of the young population (0-14 years old) in the total of population evolving from $20,54 \%$ in 1990 to $13,57 \%$ in 2010 , that is a decrease of 6,97 percentage points. The largest decrease was registered for the age group 0-14 years old with a percentage of 51,24\%.

The female population over 65 de years old, has increased in 2010 by 151057 people as opposed to 1990 , while the male population by 38568 people. The male ration shows a decrease from 78,73 man to 100 women in 1990 to 68,51 in 2010, the larges as compared to other countries (almost 10 percentage points). In spite of these, together with Romania it holds one of the first places for the ration of the number of men to 100 women. In consequence, we can say that the demographic evolution from these two countries is very similar.
For Lithuania, the type of the people pyramid is similar to the one from Romania and Bulgaria. The share of the population over 65 de years old in the total number of population has increased from $10,81 \%$ in 1990 to $16,05 \%$ in 2010, which is a similar evolution to that of Romania, from an ageing population to a demographically aged one.

The ageing took place on the bottom of the pyramid, the share of the young population (0-14 years old) in the total number of population evolving from $22,57 \%$ in 1990 to $15 \%$ in 2010 , that is a decrease of 7,57 percentage points. Here the largest decrease was registered for the age group 5-9 years old with a percentage of $45,36 \%$.

Although the people of working age are relatively constant one can notice high differences in certain age groups. Therefore, the population in the age group 40-55 years old is smaller in 1990 due to the effects of the Second World War, while the population in the interval 20-40 years old in 2010 is smaller due to the migration phenomenon.

The feminine population over 65 years old in Lithuania has increased in 2010 by 92118 as opposed to 1990 while the male population has increased by 42829 people. This fact explains why the pyramid for 2010 is slightly asymmetrical to the right. The male ration shows a decrease from 52,54 men for 100 women in 1990 to 50,96 in 2010.

And for Latvia the population pyramid shows a transition from a type 2 pyramid to a type 3 , which stand for an ageing process. The share of the population over 65 years old in the total number of population has increased from $11,82 \%$ in 1990 to $17,36 \%$ in 2010 , that is an evolution similar to the one from Romania from an ageing population to a demographically aged one.

The ageing took place on the bottom of the pyramid, the share of the young population (0-14 years old) in the total number of population evolved from $21,43 \%$ in 1990 to $13,75 \%$ in 2010 , that is a decrease by $7,68 \%$ percentage points. Here the largest decrease was registered for the age group 10-14 years old (the same as for Romania and Bulgaria) with a percentage of $44,27 \%$ )

The female population over 65 years old from Latvia increased in 2010 by 44630 as opposed to 1990 , more than the male population which registered a growth of 30189 people. The masculinity ratio shows a growth from 44,44 men for 100 women in 1990 to 48,37 in 2010.

The evolution of the ageing process in Estonia is much more similar to that from Romania and Bulgaria. The pyramid type is the same, the share of the population over 65 de years old in the total number of population has increased from $11,56 \%$ in 1990 to $17,07 \%$ in 2010 , that is an evolution from an ageing population to a demographically aged one.

The share of the young population ( $0-14$ years old) in the total number of population evolved from 22,29\% in 1990 to $15,14 \%$ in 2010 , that is a decrease of 7,15 percentage points, meaning an ageing on the bottom of the pyramid. The largest decrease was registered for the age group 10-14 years old (the same as in Romania, Bulgaria and Latvia) with a percentage of $44,99 \%$. 
In this country the female population over 65 de years old has increased in 2010 by 26789 people as opposed to 1990 , more than the male population which registered a growth of 20359 people, the masculinity ratio showing a growth from 43,35 men to 100 women in 1990 , to 49,05 in 2010 .

Poland is one $f$ the countries where the ageing process is on the bottom of the pyramid. The share of the population over 65 de years old in the total number of population has increased from $9,95 \%$ in 1990 to $13,52 \%$ in 2010 , which is a similar evolution to the one of Romania, from an ageing population to a demographically aged one. The growth in percentage points is of 3,57, which is an average value as compared to the other countries. The larges growth was registered by Latvia with $5,53 \mathrm{pp}$, and the smallest by Slovakia with 1,99 pp.

The share of the young population (0-14 years old) in the total number of population went down from $25,27 \%$ in 1990 to $15,15 \%$ in 2010 , that is a decrease of 10,12 percentage points meaning the largest decrease in the analysed countries. The largest decrease was registered for the age group 5-9 years old (the same as in Lithuania) with a percentage of $47,25 \%$.

The principle of people pyramid according to which the adult population is constant is not complied in Poland, this group of population increased by 10,48\% in 2010 as opposed to 1990 . One can notice high disparities in certain age groups. Therefore, the population from the age group 45-55 de years old from 1990 is smaller than that from 2010 due to the effects of the Second World War.

The female population over 65 de years old has increased in 2010 by 851586 people as opposed to 1990 , more than the masculine population which registered a growth of 524221 people, the masculinity ratio showing a decrease from 60,03 men to 100 women in 1990 , to 60,44 in 2010.

In Hungary we are also dealing with an ageing process. The share of the population over 65 de years old in the total number of population has increased from 13,24\% (the highest level) in 1990 to $16,61 \%$ in 2010 , meaning that the population was already aged in 1990 and the phenomenon increased in 2010 with 3,37 pp.

The share of the young population ( $0-15$ years old) in the total number of population went down from 20,54\% in 1990 to $14,75 \%$ in 2010 , that is a decrease of 5,79 percentage points meaning the slightest decrease in the analysed countries. The largest decrease was registered for the 5-9 years old age group (the same as in Lithuania and Poland) with a percentage of $26,50 \%$.

The principle of people pyramid according to which the adult people of working age remains constant is complied in Hungary, the population being identical in the two analyzed years (the only country which does not registers a growth or a decrease).

The female population over 65 years old has increased in 2010 by 208690 people as opposed to 1990, more than the masculine population which registered a growth of only 80871 people, the masculinity ratio showing a decrease from 62,31 men to 100 women in 1990 , to 57,65 in 2010. An interesting aspect for this country is the fact that the number of people above 85 years old has doubled as opposed to 1990 .

The Czech Republic also presents a demographic ageing process. The form of the pyramid evolves from a type 2 to a type 3 . The share of the population over 65 de years old in the total number of population has increased from $12,47 \%$ in 1990 to $15,22 \%$ in 2010 , meaning that the population was demographically aged in both analysed years. The growth in percentage points is of 2,75 one of the smallest growth, second after Slovakia.

The share of the young population (0-14 years old) in the total number of population went down from $21,74 \%$ in 1990 to $14,22 \%$ in 2010 , that is a decrease of 7,52 percentage points, representing the smallest decrease as compared to other countries. The largest decrease was registered for the age group 10-14 years old with a percentage of $48,66 \%$. It is remarkable the fact that in the last five years, there has been an increase in the birth rate, the bottoms of the two pyramids from the years 1990 and 2010 tend to unify. So for the age group <5 years old we have a decrease by $13,76 \%$, the smallest as compared to the other countries..

The adult population has increased by $8,74 \%$, which is explainable because the Czech Republic is one of the few countries which registered a growth in the number of population in 2010 as opposed to 1990 . This is a unique situation as compared to the other analyses; the number of female population over 65 de years old is almost identical with the number of the male population (153206, respectively 153655 people). The masculinity ration shows a growth from 60,48 men to 100 women in 1990 , to 66,85 in 2010 . In this case, similarly to Hungary, the number of people over 85 years old almost doubled in 2010 as opposed to 1990, supporting one more time the demographic ageing phenomenon.

In Slovakia there has been an ageing on the bottom of the pyramid, meaning that the birth rate decreased. The share of the young population ( $0-14$ years old) in the total number of population, experienced a tremendous decrease from $25,45 \%$ in 1990 to $15,32 \%$ in 2010 that is a decrease by 10,13 percentage points. This country together with Poland registered the largest decrease as compared to the other countries. The most obvious decrease is noticed for the population from the age group 5-9 years old, which is $42,25 \%$ smaller than the one from 1990 , followed by the age group $10-$ 14 years old with a percentage of $39,24 \%$ and the group $<5$ years old with $32,72 \%$. Al these facts show a decline of fertility with the observation that in the period 2006-2010 there has been noticed an improvement of this indicator.

We notice that the principle of the people pyramid is not complied, according to which the people of working age (1564 years old) remains relatively constant. The number of population has increased from 3398783 in 1990 to 3928471 in 2010 , that is a percentage of $15,58 \%$, the largest in the 10 analysed countries. The most spectacular growth was registered for the age groups 45-59 years old, and the smallest for the groups 15-44 years old, phenomenon which can be explained due to the decrease in the young population. Similar processes of growth were registered in Slovenia, Poland, Hungary and the Czech Republic. 
The share of the population over 65 de years old in the total number of population has increased from 10,27\% in 1990 to $12,26 \%$ in 2010 , that is an evolution similar to the one from Romania, from an ageing population to a demographically aged one. The growth in percentage points is of 1,99 that is the smallest value as compared to the other countries.

On the whole the female population over 65 years old from Slovakia has increased in 2010 by 91227 people as opposed to 1990, while the masculine population has increased by only 30992 people, meaning that the female population increased 3 times as compared to the masculine population. The masculinity ration shows a decrease from 44,75 men for 100 women in 1990 to 39,4 men in 2010.

An in Slovenia there has been an ageing process on the bottom of the pyramid due to the decrease in the birth rate. The share of the young population (0-14 years old) in the total number of population experienced a decrease from $20,95 \%$ in 1990 to $14,03 \%$ in 2010 that is a decrease of 6,92 percentage points. This country has registered one of the smallest decreases, being the second after Hungary. The most obvious decrease is noticed for the population in the age group 10-14 years old, which is $38,01 \%$ smaller than the one from 1990 , followed by the group 5-9 years old with a percentage of $35,76 \%$ and the group $<5$ years old with $18,15 \%$. All these show a decline of the birth rate with the observation that in the period 2006-2010 this indicator has considerably improved.

The principle of people pyramid according to which the adult population is relatively constant, is fulfilled in this case. The number of population increased from 1366532 in 1990 to 1421436 in 2010 , that is a percentage of $4,01 \%$, Slovenia being one of the few countries which registered growth for this type of population.

The share of the population over 65 de years old in the total number of population increased from $10,60 \%$ in 1990 to $16,53 \%$ in 2010, that is an evolution from an ageing population to a demographically aged one. The increase of 5,93 percentage points, that is the highest as compared to the other countries. These considerations show a strong ageing process.

On the whole the female population over 65 de years old from Slovenia has increased in 2010 by 67039 people as opposed to 1990, while the masculine population has increased by only 59620 people. The masculinity ratio shows a decrease from 34,37 men for 100 women in 1990 , to 30,9 in 2010 .

From the analysis we carried out above, we can distinguish the following common features regarding the demographic evolution of the 10 EU member countries in the period 19902010:

- $\quad$ The share of the young population (0-14 years old) in the total number of population has significantly increased;

- The share of the old population (65 de years old and over) in the total number of population has increased;

- The number of old women is larger than that of the men;
- The ageing process took place on the bottom of the pyramid.

In these general tendencies there are a series of disparities between the countries on the background of different socioeconomic situations.

Therefore for the young population, age group $<5$ years old, the Czech Republic and Slovenia are registering the highest decreases $(13,76 \%$ respectively $18,16 \%)$. These figures are correlated with the ones from the age groups 5-9 years old and 10-14 years old and show us that in these countries there is going to be a process of rejuvenation of the population. Taking the Czech Republic as an example we analysed the evolving trend for the age $<5$ with a parabolic model and we made a prediction for the next 6 years. The results, Fig. 3, show us the fact that around 2014 there will be a restoration of the number of people in the age group $<5$, from 1990.

On the opposite pole there is Latvia and Romania which announce a long term demographic ageing process due to the spectacular decreases $(45,25 \%$ respectively $40,03 \%)$. For the rest of the countries we notice a shy beginning of population rejuvenation, but the process will last for a long time because the number of young people has significantly decreased.

Analysing the share of the old population in the total number of population we can notice that countries as Bulgaria, the Czech Republic and Hungary used to have in 1990 a population which was already demographically aged (shares higher than 12\%). The other countries had an ageing population, with a special notice for Poland which registered the smallest share $(9,95 \%)$ in that year. Expressed in percentage points, the largest growth were registered in Slovenia $(5,93)$ and the Baltic Countries (approx. 5,5) and the smallest in the Czech Republic $(2,75)$ and Slovakia $(1,99)$.

In all these countries, the number of old female population has increased as compared to the number of men. For this chapter on the first place there is Hungary and Slovenia where the number of women is 3 times higher than the number of men, and on the opposite pole the Czech Republic where the two populations have equal values.

Comparing the level of decrease for the young population with the level of growth for the old population we can draw the conclusion that there has been an ageing process in all countries and it took place on the bottom of the pyramid. (see Def. 2).

\section{B. The Analysis of the Mortality Rate}

The mortality rate is an indicator which is used in the analysis of the ageing process of the population. Taking into account the subject of this article we have chosen the mortality rate on age and sex groups for the age group 65 de years old and over. The number of this population on the whole and sexes as well as the mortality rate is presented in Table 2 and Fig. 4.

The analysis of the data in Table 2, shows us the fact that in all countries the number of old population has increased in 2009 as opposed to 1990 . 


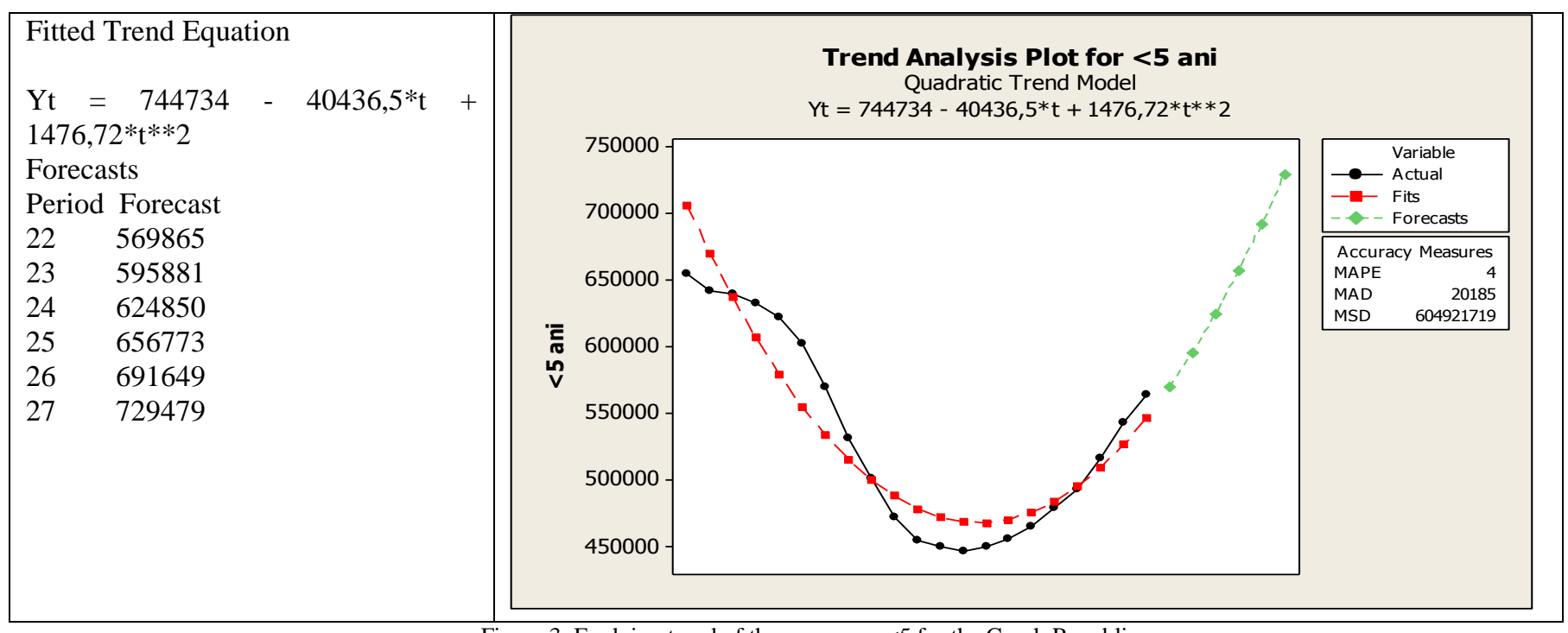

Figure 3. Evolving trend of the age group $<5$ for the Czech Republic

The largest percentage for the total number of people is registered by Slovenia with 57,85\% followed by Poland with $35,94 \%$ and Romania with $34,19 \%$. On the opposite pole there is Hungary with $19,39 \%$ and on the last place Bulgaria with only $16,51 \%$.

The situation on sexes is the same as in the case of the total number of women but there are interesting changes on the bottom. Therefore, the smallest percentage $(16,32 \%)$ goes to the Czech Republic while Bulgaria overcomes countries as Estonia, Latvia and Hungary. In the case of men, the first place goes to Slovenia with a high growth $(77,39 \%)$ followed by Estonia and Poland. On The last places there is Hungary and Bulgaria. (13,61\% respectively 7,89\%).

\begin{tabular}{|c|c|c|c|c|c|c|c|c|}
\hline \multicolumn{1}{|c|}{ MABLE 2. DATA OLD POPULATION } \\
\cline { 2 - 10 } & \multicolumn{3}{|c|}{ Males } & \multicolumn{4}{c|}{ Females } \\
\cline { 2 - 10 } & No. population & \multicolumn{2}{c|}{ No. deceases } & \multicolumn{2}{c|}{ No. population } & \multicolumn{2}{c|}{ No. deceases } \\
\cline { 2 - 10 } & $\mathbf{1 9 9 0}$ & $\mathbf{2 0 0 9}$ & $\mathbf{1 9 9 0}$ & $\mathbf{2 0 0 9}$ & $\mathbf{1 9 9 0}$ & $\mathbf{2 0 0 9}$ & $\mathbf{1 9 9 0}$ & $\mathbf{2 0 0 9}$ \\
\hline BG & 501 & 540 & 38 & 38 & 636 & 784 & 38 & 43 \\
\hline CZ & 487 & 620 & 42 & 37 & 805 & 936 & 52 & 45 \\
\hline EE & 55 & 76 & 5 & 5 & 127 & 154 & 8 & 7 \\
\hline LV & 97 & 128 & 7 & 9 & 218 & 263 & 14 & 13 \\
\hline LT & 138 & 182 & 11 & 13 & 262 & 354 & 14 & 17 \\
\hline HU & 527 & 599 & 44 & 41 & 846 & 1041 & 53 & 52 \\
\hline PL & 1420 & 1940 & 112 & 122 & 2365 & 3206 & 137 & 147 \\
\hline RO & 989 & 1299 & 72 & 88 & 1394 & 1899 & 84 & 98 \\
\hline SI & 74 & 131 & 5 & 6 & 138 & 203 & 7 & 8 \\
\hline SK & 217 & 244 & 17 & 16 & 326 & 410 & 19 & 21 \\
\hline
\end{tabular}

With respect to the total number of old deceased people in the three countries (The Czech Republic, Hungary and Slovakia) there have been registered decreases in 2009 as opposed to 1990, the most significant being in the Czech Republic of $13,44 \%$.The rest of the countries have registered growth on the first place being Romania with $22,69 \%$.
The number of female deceased persons has decreased in the Czech Republic, Estonia, Latvia and Hungary, the highest decrease of $13,52 \%$ being in Estonia. The rest of the countries experienced growth, on the first place being Romania with $16,96 \%$.

With respect to men there have been registered decreases in the Czech Republic $(13,44 \%)$, followed by Hungary and Slovakia with $6,03 \%$ respectively $4,92 \%$. The other countries experienced growth, Romania being still on the first place $22,69 \%$.

The mortality rate is analysed according to the information from Fig. 4 and in the context of the life expectancy Fig. 5. The mortality rate on the entire old population has decreased in all 10 countries but with some particularities we are going to discuss. The highest values are in the Czech Republic, Estonia and Slovenia and on the last places Romania, Bulgaria and Lithuania. The particularity lies in the fact that the Czech Republic and Estonia have experienced decreases both in the number of deceased people (with $12,97 \%$ respectively $5,84 \%$ ) and for the mortality rate (with $27,74 \%$ respectively $25,47 \%$ ). In this context if we take into account the fact that the number of old population has increased in 2009 by $20,44 \%$ respectively $26,34 \%$ we can say that in there is a demographic ageing process in the two countries and a high life expectancy. For this indicator the Czech Republic has registered a growth from 71,26 in 1990 to 76,6 in 2009, that is a growth of 5,34 percentage points, being on the last place and Estonia with a life expectance of 74,5 years old in 2009 has a growth of 4,76 years.

Slovenia had a different evolution as compared to the two countries. The decrease of the mortality rate was higher $(26,82 \%)$ but the number of deceased people has substantially raised by $15,52 \%$. This negative status was cancelled by the spectacular growth of the old population by $57,85 \%$ in 2009 as opposed to 1990, fact which has led to the demographic ageing and to a life expectancy of 78,5 years old in 2009, the highest of the analysed countries. 
The high values of the life expectancy in Slovenia and the Czech Republic are argued by the fact that the population from the age groups 80-84 de years old and over 85 de years old has increased in 2009 by almost $80 \%$ as opposed to 1990 .

Romania and Bulgaria have one of the smallest life expectancies, of 73,3 or 73,4 years. We reached this result in a different way. Romania has experienced a slight decrease of the mortality rate $(10,87 \%)$ but a high increase in the number of deceased people $(19,60 \%)$ which was cancelled by a substantial growth of the number of old people $(34,19 \%)$. Bulgaria experienced a decrease in the mortality rate of $8,09 \%$ an increased in the number of deceased people of only 7,08\% (as opposed 19,60\% in Romania) and an increase in the old population of only $16,51 \%$ in 2009 . Although the evolutions of the indicators have been contradictory, the demographic ageing process is present but with a small life expectancy. Lithuania is on the last place in what the life expectancy is concerned (72,5 years old) with an evolution close to the one of Romania.

\begin{tabular}{|c|c|c|c|c|c|c|c|c|c|c|}
\hline \multirow[b]{2}{*}{ 10,00 } & & & \multicolumn{6}{|c|}{ 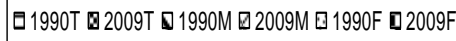 } & & \\
\hline & \multicolumn{6}{|c|}{ 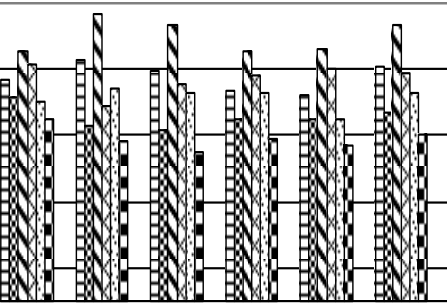 } & \multicolumn{2}{|c|}{$=$} & \multicolumn{2}{|r|}{$=$} \\
\hline$-10,00$ & $B G$ & $\mathrm{CZ}$ & $\overline{\mathrm{EE}}$ & LV & LT & $\mathrm{HU}$ & $\mathrm{PL}$ & RO & $\mathrm{SI}$ & SK \\
\hline 日1990T & 67,04 & 72,78 & 69,35 & 63,72 & 62,47 & 70,70 & 65,83 & 65,15 & 60,18 & 66,68 \\
\hline $2009 \mathrm{~T}$ & 61,62 & 52,59 & 51,68 & 55,11 & 55,02 & 57,14 & 52,23 & 58,07 & 44,04 & 57,06 \\
\hline $\mathbf{D} 1990 \mathrm{M}$ & 75,70 & 86,63 & 83,69 & 75,43 & 76,33 & 83,35 & 79,07 & 72,43 & 73,70 & 79,77 \\
\hline $2009 \mathrm{M}$ & 71,20 & 58,92 & 65,28 & 68,32 & 70,18 & 68,94 & 62,68 & 67,66 & 49,20 & 67,57 \\
\hline Q 1990F & 60,22 & 64,40 & 63,13 & 62,64 & 55,19 & 62,82 & 57,87 & 59,99 & 52,96 & 57,95 \\
\hline $2009 \mathrm{~F}$ & 55,01 & 48,39 & 44,99 & 48,70 & 47,24 & 50,35 & 45,90 & 51,51 & 40,72 & 50,81 \\
\hline
\end{tabular}

Figure 4. Mortality rate per total and per sexes for old population

The mortality rate on sexes for the old population has decreased in all 10 countries both for the female and the male population fact which shows a process of demographic ageing.

For the female population, the highest decreases for the mortality rate were registered in the Czech Republic and Estonia $(24,85 \%$ and $28,74 \%)$, which correlated with the decrease in the number of deceased population $(12,58 \%$ and $13,52 \%)$ and a moderate increase of the old population $(16,32 \%$ and $21,36 \%)$ led to a process of demographic ageing for the female population and to a life expectancy of 79,7 respectively 79,5 years old, being overcome by Slovenia with 81,9 years old. As for the total of old population, Slovenia registered a high mortality $(23,10 \%)$, but as compared to the other two countries an increase in the number of deceased persons (cu 13,36\%) compensated by a high increase in the feminine population $(47,42 \%)$. We have to notice for this type of population the life expectancy in Poland (79,5 years old) is identical with that from Estonia but the evolution of the indicators is not similar but is follows the trend of the one from Slovenia.

Romania and Bulgaria are on the last two places with a decrease of the mortality rate of only $14,3 \%$ respectively $8,65 \%$. The other indicators have similar evolution with the one from the old population and led to a life expectancy on only 77,1 respectively 77,0 years old.

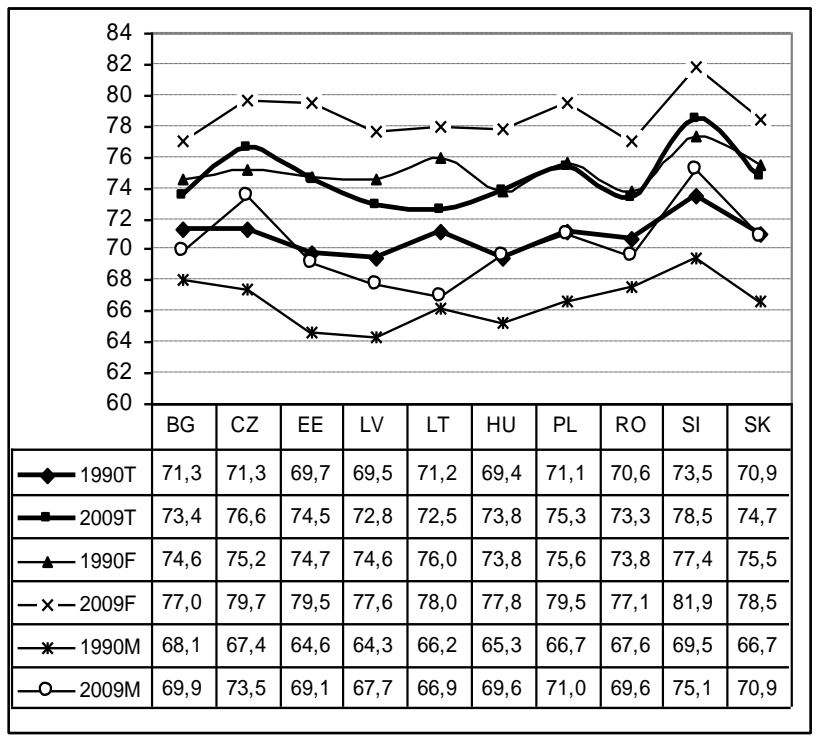

Figure 5. Life expectancy at birth

For the male population the highest decrease in the mortality rate was registered in Slovenia (with $33,25 \%$ ) but also an increase in the number of deceases of $18,41 \%$. This data correlated with the high increase in the number of old population $(77,39 \%)$ make Slovenia the country with the highest life expectancy, 75,1 years old. On the second place there is the Czech Republic with 73,5 years old, but as compared to Slovenia there is also a decrease in the number of deceased persons. The evolution of the two countries is similar with the ones registered in the feminine population and old population.

Romania and Bulgaria are not on the last places, these being occupied by Estonia, Latvia and Lithuania. The surprising emergence of Estonia in this category is due to the fact that there has been a growth by 7,50\% in the number of deceased people. Lithuania is on the last place for the life expectancy with 66,9 years old, under the circumstances of a mortality rate with a modest decrease of $8,06 \%$ but a strong growth of the number of deceased people $(21,50 \%)$.

\section{Demographic dependencies. Implications}

The analysis of the demographic ageing process requires the study of the demographic dependency indicator $[3,8,9]$, due to its social and economic implications.

Therefore the growth of the percentage of population over 65 years old and on the total determines the decrease of the share in the other age groups, and tends to create social and economic pressures determined by the change of the way of granting the resources in the society. In Table 3 we present the 
old age dependency rates [relation 5] for the years 1990 and 2010 .

A high demographic dependency rate indicates the fact that a high number of beneficiaries of public health and retirement systems will be "supported" by a low number of tax payers, the analysis of these aspect were done in [4]. Therefore the old people of working age will be "burdened" to pay higher taxes and contributions which should provide the retired people a stable and sufficient income. In other words there will be a decrease in the living standard of the population.

TABLE 3. DEPENDENCY RATE FOR OLD PEOPLE

\begin{tabular}{|c|c|c|r|r|r|r|}
\hline & \multicolumn{2}{|c|}{$\begin{array}{c}\text { People of working age } \\
\text { (15-64) }\end{array}$} & \multicolumn{2}{c|}{ Old population (65+) } & \multicolumn{2}{|c|}{ Rdv } \\
\cline { 2 - 7 } & $\mathbf{1 9 9 0}$ & $\mathbf{2 0 1 0}$ & $\mathbf{1 9 9 0}$ & $\mathbf{2 0 1 0}$ & $\mathbf{1 9 9 0}$ & $\mathbf{2 0 1 0}$ \\
\hline BG & 5830075 & 5211619 & 1136266 & 1325891 & 19,49 & 25,44 \\
\hline CZ & 6817371 & 7413560 & 1292022 & 1598883 & 18,95 & 21,57 \\
\hline EE & 1038860 & 908466 & 181605 & 228753 & 17,48 & 25,18 \\
\hline LV & 1780927 & 1549011 & 315390 & 390209 & 17,71 & 25,19 \\
\hline LT & 2460639 & 2295339 & 399454 & 534401 & 16,23 & 23,28 \\
\hline HU & 6870352 & 6873985 & 1373922 & 1663483 & 20,00 & 24,20 \\
\hline PL & 24639820 & 27223082 & 3785663 & 5161470 & 15,36 & 18,96 \\
\hline RO & 15319481 & 15003660 & 2383435 & 3206408 & 15,56 & 21,37 \\
\hline SI & 1366532 & 1421436 & 211606 & 338265 & 15,48 & 23,80 \\
\hline SK & 3398783 & 3928471 & 542915 & 665134 & 15,97 & 16,93 \\
\hline
\end{tabular}

The comparative analysis of the data from Table 2 shows a series of interesting aspects. Slovenia presents the highest growth for the dependency rate (8,31 percentage points) although the adult population has increased. It is the country with the highest pressure exerted by the old population on the people of working age. Here we can see a strong process of demographic ageing, fact which was underlined above, where we showed that the share of the old population increased in 2010 by 5,93 percentage points as opposed to 1990 (the largest growth as compared to the analysed countries).

For the Czech Republic, Poland and Slovakia there is also a growth in the number of people of working age, but the dependency rates have increased with less percentage points( 2,62 for the Czech Republic, 3,60 for Poland and 0,96 for Slovenia), which shows us a moderate process of demographic ageing. Hungary is also in this category - with an adult population almost identical it registered a growth in the dependency rate by 4,20 percentage points.

Romania and Bulgaria show a decrease in the number of people of working age and at the same time the dependency rates have significantly increase in percentage points by 5,81 and 5,95. We can conclude that in these countries there is a high pressure of the old population on adult population. There is a demographic ageing process in these countries as well.

The most difficult situation is registered for the Baltic Countries which register decreases for the number of people of working age and high growth for the demographic dependency rate, fact which indicates a strong ageing process of the population and a strong pressure on the adult population. The causality ratios between the people of people of working age (PVM) and the population over 65 years old (P65+) can be quantified and analysed with the help of regression and correlation.

The data to be analyzed, Fig. 6, are taken from EUROSTAT and represent the 1990-2010. Using the linear regression where PVM is the factorial variable and $\mathrm{P} 65+$ the resulting variable and the analysis and data processing program MINITAB 14.1, we will obtain the following information for Romania:

\section{Regression Analysis: P65+ versus PVM}

The regression equation is

\begin{tabular}{lllcc}
\multicolumn{2}{l}{ P65+=20486378 $-1,15 \cdot \mathrm{PVM}$} \\
Predictor & Coef & SE Coef & T & P \\
Constant & 20486378 & 4860702 & 4,21 & 0,000469 \\
PVM & $-1,15$ & 0,320301 & $-3,61$ & 0,001834 \\
R-Sq $=40,7 \%$ & & &
\end{tabular}

Correlations: P65+; PVM

Pearson correlation $(r)=-0,63$

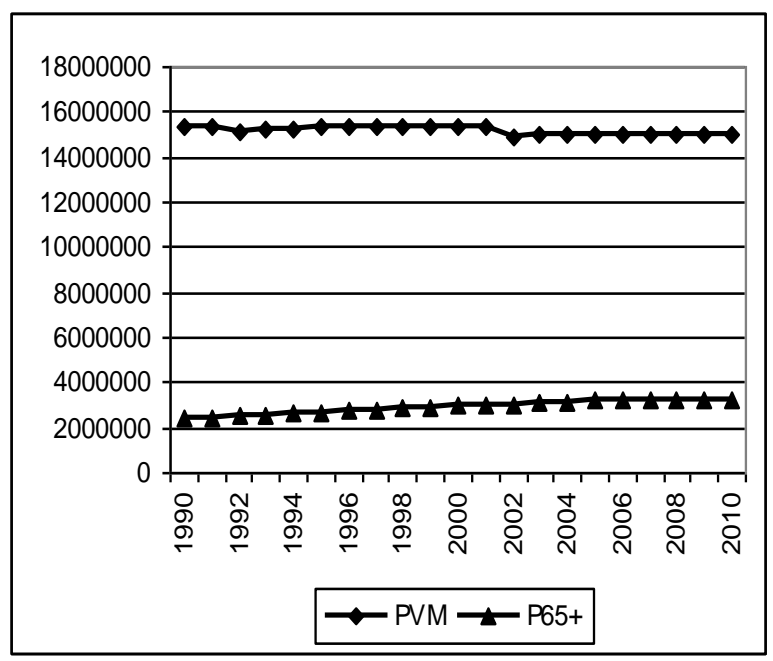

Figure 6. Evolution of indicators PVM and P65+ in Romania

The value of the determination coefficient ( $\mathrm{R}-\mathrm{Sq}$ ), points out the fact that PVM (number of people of working age) influences $\mathrm{P} 65+$ (number of old population) in proportion of $40,7 \%$.

At the same time the value of the correlation coefficient $r$ $(-0,63)$ shows a reverse correlation with average intensity. The signification of this result is noticed with the help of the test Student $(t)$, where $t_{\text {calc }}$ calculated with relation 13 has the value $-3,617$. The tabular value of $t$ for 21-2 degrees of freedom and $\alpha / 2=0,025$ is: 2,093 (respectively $-2,093$ ).

As the value of $t_{\text {calc }}$ is outside the interval of the tabular values it means that $r$ is significant, that is there is a significant connection between the two variables or in other words the correlation coefficient is statistically significant.

We can notice that the value of the constant parameter $a$ is very high (20486378) and that the determination coefficient has a modest value $(0,407)$ meaning that other factors are influencing the number of old population. For example we might use the multiple regression with two factorial 
parameters (PVM and the life expectancy-SV) obtaining the following results:

The regression equation is

$\mathrm{P} 65+=-3534847-0,285 \mathrm{PVM}+150851 \mathrm{SV}$

$\begin{array}{lllrc}\text { Predictor } & \text { Coef } & \text { SE Coef } & \text { T } & \text { P } \\ \text { Constant } & -3534847 & 7181243 & -0,49 & 0,629 \\ \text { PVM } & -0,2846 & 0,3303 & -0,86 & 0,400 \\ \text { SV } & 150851 & 38731 & 3,89 & 0,001\end{array}$

$\mathrm{R}-\mathrm{Sq}=67,9 \%$

Correlations: PVM; SV; P65+

$$
\begin{array}{lrc} 
& \text { PVM } & \text { SV } \\
\text { SV } & -0,679 & \\
\text { P65+ } & -0,639 & 0,816
\end{array}
$$

In this case the determination coefficient has substantially increased showing the fact that PVM and SV are influencing P65+ in a proportion of $67,9 \%$. The partial correlation coefficient for the life expectancy $\left(\mathrm{r}_{\mathrm{P} 65+, \mathrm{SV}}\right)$ has a very high positive value $(0,816)$, meaning that between the variations of the two variables (P65+ and SV) there is a direct strong connection. The partial correlation coefficient for PVM $\left(\mathrm{r}_{\mathrm{P} 65+, \mathrm{PVM}}\right)$ has a moderate negative value $(-0,639)$, meaning that between the variations of the two variables $(\mathrm{P} 65+$ şi PVM) there is a reverse connection of average intensity. The compound correlation coefficient $r_{\mathrm{SV}, \mathrm{PVM}}$, for the two factorial variables-PVM şi SV- has a value of $-0,679$ pointing out a reverse moderate intensity connection.

Working in a similar way for the other countries we obtain a series of information regarding the correlation between the two variables, Table 4.

\begin{tabular}{|c|c|c|c|c|}
\hline & Regression equation & R-Sq ( \%) & $\mathbf{r}$ & $\mathbf{t}_{\text {calc }}$ \\
\hline BG & $\mathrm{P} 65+=2873139-0,28 \cdot \mathrm{PVM}$ & 70,6 & $-0,84$ & $-6,757$ \\
\hline $\mathbf{C Z}$ & $\mathrm{P} 65+=-1569689+0,41 \cdot \mathrm{PVM}$ & 92,7 & 0,96 & 15,625 \\
\hline EE & $\mathrm{P} 65+=491010,1-0,30 \cdot \mathrm{PVM}$ & 65,6 & $-0,81$ & $-6,032$ \\
\hline LV & $\mathrm{P} 65+=890211,1-0,32 \cdot \mathrm{PVM}$ & 79,0 & $-0,88$ & $-8,462$ \\
\hline LT & $\mathrm{P} 65+=2205327 \quad-0,73 \cdot \mathrm{PVM}$ & 87,8 & $-0,88$ & $-11,718$ \\
\hline $\mathrm{HU}$ & $\mathrm{P} 65+=5652582 \quad-0,59 \cdot \mathrm{PVM}$ & 6,45 & $-0,25$ & $-1,144$ \\
\hline PL & $\mathrm{P} 65+=-9843770+0,55 \cdot \mathrm{PVM}$ & 99,7 & 0,99 & 44,991 \\
\hline RO & $\mathrm{P} 65+=20486378-1,15 \cdot \mathrm{PVM}$ & 40,7 & $-0,63$ & $-3,617$ \\
\hline SI & $\mathrm{P} 65+=-3274244+2,54 \cdot \mathrm{PVM}$ & 94,7 & 0,97 & 18,577 \\
\hline SK & $\mathrm{P} 65+=-130823+0,19 \cdot \mathrm{PVM}$ & 96,9 & 0,98 & 24,56 \\
\hline
\end{tabular}

TABLE 4. PARAMETERS OF THE REGRESSION EQUATION AND THE CORRELATION COEFFICIENTS

From the analysis of the data from Table 4 from the point of view of the determination coefficient (R-Sq) we can notice that Hungary has the smallest coefficient, adult population has an insignificant influence on the number of old population, which means that other factors have influenced this number. For example the growth of the living standard which led to the growth of the life expectancy, Hungary registering an important performance for this chapter. The life expectancy for men has increase from 64,29 years old in 1990 to 68,7 years old in 2009, and for women from 72,84 years old to 76,8 years old; with an average of 4,2 years it holds the third place after the Czech Republic and Slovenia.

Romania is on the second place in this classification with a determination coefficient of only 0,407 which shows that the influence of other factors on the number of old people is pretty high $(59,3 \%)$. This situation is pointed out by the very high value (20486378) of the parameter $a$ (intercept) for the regression equation.

On the opposite pole there is a group of countries (The Czech Republic, Poland, Slovenia and Slovakia) where the influence of the active population on the old population is above $90 \%$, which is other factors have a slight influence. Poland is remarkable with an influence percentage of $99,7 \%$ and shows us that the number of old population was determined exclusively by the people of working age number.

There is a group of countries between these extremes (Bulgaria, Estonia, Latvia, Lithuania) where the determination coefficient has a moderate value, suggesting the fact that other factors have a pretty high influence on the number of old population.

The intensity and sense of the correlation between the two variables is analysed through the correlation coefficient. The intensity level was refined on intervals of values from a strong, functional connection to a weak one or to the inexistence of a connection.

Bulgaria, Estonia, Lithuania, Latvia, Hungary and Romania present a reverse correlation between the variables with the following intensities: Hungary, very weak intensity ($0,25)$, almost non-existing, Romania has an average intensity and the other countries a strong intensity.

The Czech Republic, Slovakia and Slovenia present a direct correlation with high values of the correlation coefficient (above 0,95) indicating a functional connection between the two variables.

The significance of the above results is pointed out with the help of the statistical test Student(t). Therefore, all analysed countries except for Hungary have the value of $t_{\text {calc }}$ outside the interval of the tabular values that is the null hypothesis is rejected and between the variables there is a causal connection. Hungary has a value of $t_{\text {calc }}$ of $-1,144$ situated in the interval of the tabular values, meaning that this null hypothesis is accepted, in other words there is no causality relation between the two variables.

\section{CONCLUSIONS}

This study pointed out the way in which different population parameters have evolved in the former-communist countries and their implications of the social environment. It was notices that some of the data was influenced by the economic and political evolution and in some cases there were major interferences between the evolution of the population and that of the involved parameters. The obtained results show the fact that in the former-communist countries we see a growing ageing phenomenon which exists in the other EU 
countries, but the determining factor for the first group of countries is the severe decrease of the birth rate after the removal of the restrictive policies regarding abortions (after 1990).All these data rely on official EU sources (EUROSTAT) and their analysis has been made using mathematical analysis methods for demographic statistics and analysis and statistical data processing software. Without the claim of having discussed all the interpretative valences of the phenomenon, our intention is to further study the implications on the economies of the states with which of studied countries have economic relations and their social motivations, using non-linear models from the statistical mathematics.

\section{REFERENCES}

[1] R. H. Binstock, K. G. Linda (Editors), "Handbook of Aging and the Social Sciences", 7th Edition, Academic Press, 2010

[2] G. Calot, J.-P. Sardon, "Methodology for the calculation of Eurostat's demographic indicators", Eurostat, 2003

[3] H. Engelhardt, H.-P. Kohler, A. Prskawetz, "Causal Analysis in Population Studies: Concepts, Methods, Applications”, Springer, 2009

[4] J. Grant et all, "Low Fertility and Population Ageing Causes, Consequences and Policy Options", RAND Europe Report of European Commission, 2004
[5] A. Haupt, T. Kane, "Population Handbook", Population Reference Bureau, 5rd edition, Washington, 2004

[6] M. M. Howard, "The Weakness of Postcommunist Civil Society", Cambridge University Press, 2002

[7] G. Keller, B. Warrack, "Statistics for Management and Economics", Academic I. Pub Inc, 2006

[8] W. Lutz, "Recent Demographic Trends in Europe and the World", European Demographic Forum, 2008

[9] R. Moffitt, "Remarks on the Analysis of Causal Relationships in Population Research, Demography", no. 42, 2005

[10] L. A. Morgan, S. R. Kunkel, "Aging, Society, and the Life Course", Fourth Edition Springer Publishing Company, 2011

[11] S. H. Preston, P. Heuveline, M. Guillot, "Demography: Measuring and Modelling Population Processes", Blackwell Publishing. 2001

[12] ***http://epp.eurostat.ec.europa.eu/portal/page/portal/statistics/search_d atabase

\section{AUTHORS PROFILE}

Dorel Săvulea: He is Lecturer at University of Craiova, Faculty of Exact Sciences, Department of Informatics. His area of expertise is in the domain of economic process analysis.

Nicolae Constantinescu: He is Associate Professor at University of Craiova, Faculty of Exact Sciences, Department of Informatics and his area of expertise is mathematically models of cryptography and statistics analyses. 